\title{
Escritos de Lygia Pape: cidade, neovanguarda e cultura material popular
}

\author{
Vanessa Rosa Machado, Fábio Lopes de Souza Santos*
}

Resumo Conhecida por obras neoconcretas e pela experimentação dos anos 1960 e 1970, a artista carioca Lygia Pape (1927-2004) manteve um interesse constante pela cultura não erudita. Destacam-se neste artigo três de seus pouco conhecidos escritos: "Tramas de caboclo ou a geometria do mato" (s/d), "Favela da Maré ou milagre das palafitas" (1972) e "A mulher na iconografia de massa" (1978). Em conjunto, revelam tanto uma abordagem original e positiva sobre essa produção, visão que compartilhou com seu amigo e interlocutor Hélio Oiticica, quanto uma inflexão em seu interesse inicial pelo popular urbano, que se desloca em direção à cultura de massa.

Palavras-chave: Lygia Pape, produção textual, cultura popular urbana.

\section{Writings of Lygia Pape: city, "neovanguard" and popular material culture}

Abstract Known for her neoconcrete works and for the ex-
perimentation of the 1960s and 1970s, the brazilian artist
Lygia Pape (1927-2004) maintained a constant interest
in popular culture. In this article, three of her little-known
writings are analyzed: "Tramas de caboclo ou a geometria
do mato" (s/d), "Favela da Maré ou milagre das palafitas"
(1972) and "A mulher na iconografia de massa" (1978).
Together, they reveal both an original and positive approach
to this production, a shared vision with her friend and inter-
locutor Hélio Oiticica, as well as an inflection of her interests
in the urban popular, which moves toward mass culture. Key words: Lygia Pape, text production, urban popular culture.

\section{Escritos de Lygia Pape: ciudad, neovanguardia y cultura material popular}

Resumen Conocida por obras neoconcretas y por la experimentación de los años 1960 y 1970, la artista brasileña Lygia Pape (1927-2004) mantuvo un interés constante por la cultura no erudita. Se destacan en este artículo tres de sus poco conocidos escritos: "Tramas de caboclo ou a geometria do mato" (s/d), "Favela da Maré ou milagre das palafitas" (1972) y "A mulher na iconografia de massa" (1978). En conjunto, revelan tanto un enfoque original y positivo sobre esa producción, visión que compartió con su amigo e interlocutor Hélio Oiticica, como una inflexión en su interés inicial por el popular urbano, que se desplaza hacia la cultura de masa.

Palavras clave: Lygia Pape, producción textual, cultura popular urbana. 
* Vanessa Rosa Machado é Arquiteta e Urbanista, doutora em Teoria e História da Arquitetura e do Urbanismo, ORCID: <https://orcid.org/0000-00033607-1604>; Fábio Lopes de Souza Santos é Arquiteto e Urbanista, professor do Instituto de Arquitetura e Urbanismo da USP, ORCID: <https://orcid.org/00000002-2189-4619>.

1 É nos escritos de Ortega (2004) que encontramos primeiramente aproximações entre a produção de Pape e a cultura do índio. A autora aproxima as xilogravuras "Tecelares" à pintura corporal indígena, da etnia Kayapó-xicrin, e analisa suas obras em referência aos tupinambás. Segundo a autora, chamando a atenção para esta referência, Pape visaria colocar em debate a própria condição humana. artista brasileira Lygia Pape (1927-2004) produziu continuamente desde o início da década de 1950 até meados dos anos 2000. Seu trabalho, extenso e diversificado, foi marcado pelas constantes reformulações das linguagens que investigava.

Entre as atividades que desenvolveu estiveram a gravura, a pintura, o cinema, a programação visual, o design, eventos e performances, instalações ambientais e objetos.

Apesar da possibilidade de encontrar algumas linhas constantes em sua trajetória, como o trabalho com a palavra e com o movimento (como nos "livros" e "balés" neoconcretos), com eventos participativos (a exemplo de "Ovo", "Divisor" e "Roda dos Prazeres"), com a construção poética de espaços (como em "Tteias" e "Espaços Imantados"), com o tratamento de questões da história do Brasil (em "Mantos tupinambás" e "Carandiru", por exemplo) ou com a relação entre o feminino e o consumismo (como no projeto "Eat me: a gula ou a luxúria?"), não é possível dizer que Pape trabalhasse a partir de predeterminações, mas que se movimentava por diferentes áreas, temas e técnicas - ela mesma brincava que já havia sido "concreta", "neoconcreta" e que mais recentemente era "free-lancer" (PAPE, 1998, p.22).

De sua trajetória, a produção concreta e neoconcreta é a mais conhecida. Pape integrou o Grupo Frente, liderado por Ivan Serpa, entre 1954 e 1956. Essa vertente carioca do concretismo é vista como menos comprometida com os ideais da Bauhaus e da Escola de Ulm que a do Grupo Ruptura (1952), de São Paulo. Por essa época, as composições abstrato-geométricas buscavam se afinar à modernidade e industrialização em curso no país. Era comum aos artistas utilizar cores padronizadas e tinta em spray para fazer sumir traços mais pessoais, como as pinceladas, nas composições.

Contudo, Pape, a partir de 1955, se embrenhou na execução de composições geométricas em xilogravuras sobre papel manteiga, às quais chamou de "Tecelares".

Entre os artistas do Grupo Frente era a única a produzir xilogravuras, a trabalhar numa técnica artesanal no momento de ampla modernização dos anos 1950. As "Tecelares" (1955) representam o esforço em imprimir rigor construtivo a uma técnica tradicionalmente artesanal e associada à literatura de cordel nordestina. Ressalta nelas ainda a referência às formas geométricas da pintura corporal indígena (ORTEGA, 2004) ${ }^{1}$. Ao vincular arte moderna e arte indígena, Pape procurava, por um lado, seguindo uma conhecida tática modernista, "voltar ao início das coisas" (PAPE, 1998, p 17) e, por outro, dar continuidade ao projeto do Modernismo brasileiro de sintetizar a arte internacional avançada e os elementos nacionais.

Essa curiosa dissonância, trabalhar numa técnica artesanal no momento em que se exploravam técnicas e linguagens próximas à indústria, revela o interesse que manteve durante toda sua longa produção pela cultura material popular. Certa vez, falando sobre isso, Lygia afirmou que "não há nada mais sofisticado, intelectualmente falando, 
do que a cultura dita não erudita. A proximidade com as manifestações populares diz respeito à percepção do mundo que eu tenho como artista" (PAPE, 1998, p. 21-22).

Essa particularidade, além de a distinguir frente a seus pares, também a coloca próxima ao seu amigo e interlocutor Hélio Oiticica, cuja produção é bastante lembrada pela proximidade que manteve à cultura do morro da Mangueira nos anos 1960.

Lygia Pape compartilhou com Oiticica essa experiência pela cidade "informal" . Narrou em entrevista os "delírios ambulatórios" pela Mangueira e por outras regiões da cidade. Os delírios davam-se frequentemente pelas andanças de carro sem programação prévia no fusca café-com-leite de Lygia Pape durante as madrugadas do Rio de Janeiro: "Ele [Hélio] me dizia: vamos curtir. O delírio ambulatório era isso: você saia pela cidade toda, que não tinha perigo nenhum, e ia descobrindo as coisas, vendo e vivendo" (MATTAR, 2003, p.75).

Lygia e Hélio viam potencialidades na inusitada riqueza dos espaços urbanos não planejados e valorizavam as qualidades de uma cidade que poderia ser fonte de experimentações estéticas que incluíam o movimento, a dança e a permeabilidade entre espaços públicos e privados.

Narrando suas experiências na Mangueira, Lygia declarou:

Eu também gostava muito de subir os viadutos ali perto da Praça da Bandeira, porque era uma espécie de cruzamento de corpos, e depois íamos para a Mangueira. [...] Então a gente ia porque lá estavam aqueles malandrões todos. [...] la lá em cima no telégrafo, subia com o Hélio, nós tínhamos amigos em vários grupos ali dentro. Me dava um prazer enorme sair por ali e estar com eles. (MATTAR, 2003, p. 76-77)

Reflexos dessas vivências podem ser encontrados em sua pesquisa e atividade docente. Durante longo período, Pape se dedicou ao ensino. Deu aulas de arte no curso livre do Museu de Arte Moderna-RJ de 1969 a 1971 e de 1976 a 1977 na Escola de Artes Visuais do Parque Lage, de 1972 a 1985 de Semiótica do Espaço e Plástica para os alunos do curso de Arquitetura da Universidade Santa Úrsula, e ainda lecionou disciplinas relacionadas ao desenho na Escola de Belas Artes da Universidade Federal do Rio de Janeiro de 1982 a 1989.

Para os alunos do curso de Arquitetura, Pape idealizou aulas baseadas na vivência de espaços da "cidade informal", chamando a atenção para a paradoxal riqueza dos espaços criados pela precariedade. Além do Morro da Mangueira e da Favela da Maré, onde realizou um filme ("Favela da Maré", 1982, super-8), chamaram a atenção de Lygia a Baixada Fluminense, o bairro de Madureira e o mercado do Saara.

Como Hélio Oiticica, Lygia Pape, além da produção artística, também escreveu. Sua produção textual é ainda pouco estudada e inclui análises teóricas das suas próprias obras e também - e esta é a parte que mais importa para nossa argumentação análises da arquitetura e de objetos populares, de construções indígenas e da presença marcante da cor na arquitetura popular. Destacaremos três textos em que Pape analisa, de forma bastante original, aspectos da cidade e da paisagem urbana. 
2 Podemos considerar que seu trabalho acadêmico seja parte de um conjunto de produções que iluminaram o fazer artesanal e a cultura de povos indígenas, como os filmes "A mão do povo" (1975), sobre os saberes populares e "Catiti catiti" (1978), uma reflexão sociológica sobre os contrastes do país, os "Mantos Tupinambás" (1996-1999) e o projeto que tinha junto a Mário Pedrosa de fazer uma exposição no MAM - Rio de Janeiro sobre o índio brasileiro. Como apontou Osório (2006), a produção acadêmica de Pape, assim como seus trabalhos artísticos, trazem visibilidade à resistência cultural de grupos marginalizados.
3 Esses e outros textos da artista foram publicados na compilação "Lygia Pape - Espaço Imantado" pela ocasião das exposições de mesmo nome ocorridas na Pinacoteca do Estado de São Paulo (17 de março a 13 de maio de 2012), Serpentine Gallery, Londres (7 de dezembro de 2011 a 19 de fevereiro de 2012) e Museo Nacional Centro de Arte Reina Sofia, Madri (24 de maio a 3 de outubro de 2011). Ver: BORJASVILLEL, Manuel J.; VELÁSQUEZ, Teresa. (curadoria). Lygia Pape: espaço imantado. Textos de Paulo Herkenhoff [et al.]. São Paulo: Pinacoteca do Estado, 2012.
De início, veremos dois pequenos textos, "Tramas de caboclo ou a geometria do mato" (s/d) e "Favela da Maré ou milagre das palafitas" (1972), que mostram sua visão sobre a produção popular de arquitetura. Esses textos dialogam com argumentos desenvolvidos por Pape em sua dissertação de mestrado, "Catiti catiti, na terra dos brasis", escrita em 1980 para a Universidade Federal do Rio de Janeiro, da qual recobraremos algumas ideias centrais².

O terceiro texto, "A mulher na iconografia de massa", mais extenso, é o resultado de um projeto de pesquisa que Pape realizou para a FUNARTE em 1978 e, conforme a própria artista definiu, integra o projeto "Eat me: a gula ou a luxúria?", composto por um filme ("Eat me", 1975) e duas exposições com o mesmo nome (1975, Galeria Arte Global, São Paulo e 1976, MAM-RJ) que tratam da justaposição entre o consumo e a condição feminina. Este texto refere-se a questões, por assim dizer, mais "contemporâneas", pois trata do avanço da prática da indústria cultural, que passava a modificar a experiência urbana.

A partir desses textos, se percebem duas abordagens distintas sobre a produção de arquitetura e da cidade. Contudo, embora divergentes, ambas se relacionam à visão "de artista" de Pape. Em "Tramas de caboclo..." e "Favela da Maré..." seu enfoque mescla o repertório vindo das artes plásticas à análise dos espaços das habitações populares feitas de pau-a-pique ou construídas sobre palafitas - leitura original frente à visão em voga no período sobre o "popular". Já em "A mulher na iconografia de massa", diante do uso comercial da imagem da mulher na publicidade, a artista aponta para outras formas de leitura da paisagem urbana, demostrando a possibilidade de driblar as estratégias do consumismo.

Interessa-nos explorar a maneira como a artista trabalha a partir desses dois universos distintos num curto espaço de tempo, usando referências que parecem apontar para direções opostas.

A importância destes textos reside em que revelam tanto as posições de artistas diante da produção de arquitetura e da cidade quanto aludem a dilemas sócio-políticos do período em que foram produzidos. Passemos à sua leitura.

\section{"Tramas de caboclo ou a geometria do mato" (s/d) e "Favela da Maré ou milagre das palafitas" (1972)}

O fascínio de Pape pelas construções populares se fez presente num pequeno texto, de apenas uma página, chamado "Tramas de caboclo ou a geometria do mato" que apresenta brevemente um incipiente projeto de pesquisa sobre as "casas de caboclo" feitas de pau-a-pique: "O projeto que apresentamos pretende mostrar um segmento quase anônimo do processo de criação do homem-do-povo: as casas de caboclo" (PAPE, s/d in BORJAS-VILLEL; VELÁSQUEZ, 2012, p.286).

Nas palavras de Pape, o caboclo teria herdado a tradição vinda do índio na forma como trança o bambu ou os ramos em um gesto "quase sistêmico", e posteriormente a do branco, de quem viria a elaboração da vedação das paredes com o barro amassado. Pape inicia descrevendo as etapas da construção da casa ou, como chama, o "processo de criação do homem-do-povo", o qual envolveria uma "poética própria". O primeiro 
passo seria a confecção de gaiolas feitas de bambu, que receberiam o barro amassado "jogado aos sopapos" pelas frestas. Nessa leitura, ganha destaque a geometria presente nos desenhos das tramas:

[...] deixando o rendilhado dos bambus ou ramos aflorar traçando os desenhos de padrão muito próximo de uma postura construtivista, ou seja, rudimentos que informam sobre um desejo de ordem plástica marcado pela diversidade dos modelos: diagonais paralelas, triângulos, quadrados modulando os planos. (PAPE, s/d in BORJAS-VILLEL; VELÁSQUEZ, 2012, p.286)

A postura, conforme suas palavras, próxima à dos construtivistas, é positivamente vista como um "desejo de ordem plástica" e o "ato construtivo" é destacado nesse exemplo de construção como exercício de uma racionalidade específica:

Esses objetos-de-geometria ordenam a paisagem em ritmos que escapam ao mero acaso e determinam que a mão-do-povo registra uma sensibilidade especial para o abstracionismo geométrico, que podemos também encontrar nas manifestações dos índios, do negro, nos objetos reciclados das feiras nordestinas como brinquedos, fifós, etc. (PAPE, s/d in BORJAS-VILLEL; VELÁSQUEZ, 2012, p.286)

Conclui "Tramas de caboclo..." relacionando esses "objetos-de-geometria" à arte dos construtivistas brasileiros, concretos e neoconcretos:

Poderíamos dizer que essas referências culturais vão relacionar-se com a arte dos construtivistas brasileiros nos movimentos concreto e neoconcreto que não teriam, portanto, tantas referências internacionais como poderia se pensar.

Há dentro da cultura brasileira uma identidade própria que define o fazer do artista tanto erudito quanto o popular como dois polos de um mesmo princípio: o tropismo pelo geométrico, de forma consciente ou intuitiva. Ambos dão um caráter de força e identidade a toda criação brasileira. (PAPE, s/d in BORJAS-VILLEL; VELÁSQUEZ, 2012, p.286, grifo nosso)

Essa argumentação, a de que nas manifestações populares se encontraria uma linguagem próxima à adotada no Projeto Construtivo Brasileiro, Pape desenvolveu na primeira parte de sua dissertação, no capítulo intitulado "Concretos e Neoconcretos", o segundo da primeira parte, chamada "A crise da arte". Nele, Pape justifica a autonomia da atuação da vanguarda construtiva brasileira frente às correntes internacionais. Seu texto configura um elogio a essas tendências, enaltecendo-as como o segundo momento decisivo da criação de "uma consciência brasileira na arte" (o primeiro fora o Movimento Antropofágico). No capítulo, Pape responde à parte da crítica nacional que considera o "Projeto construtivo brasileiro" uma "assimilação irresponsável e epidérmica de correntes internacionais" reafirmando a existência de um "tropismo construtivo na arte brasileira", presente: "no índio, no africano, no objeto reciclado do nordestino, na permanência de elementos geométricos dos carnavais, nas colchas de retalho mineiras, nas cerâmicas populares, na arquitetura espontânea de beira de praia, etc." (PAPE, 1980, p.22), num tom bastante próximo ao que empregara em "Tramas de caboclo...". 
4 Em "Catiti catiti", escrevendo sobre as qualidades estéticas do artesanato rural, Pape chegou a afirmar que "No Vale do Jequitinhonha em Minas Gerais, reduto de pobreza incrível, o homem do povo, fabrica ele mesmo seus objetos de uso. E os faz primorosos, de uma qualidade técnica e artística dignos de um Picasso por exemplo" (PAPE, 1980, p.65).

5 Esse recurso de linguagem Pape também usou para descrever a forma de ocupação das favelas nos morros em "Catiti catiti": "Formam-se gestalts, signos identificadores, as manchas nos morros das cidades, como enormes fungos, cobrem e recobrem as topologias - e ele cria: sempre e sempre um objeto 'que partici-

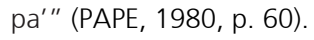

A geometria presente nas manifestações da produção popular justificaria a adoção da abstração geométrica entre concretos e neoconcretos. Presente na cultura "genuinamente brasileira", como as construções de pau-a-pique, ela testemunharia nossa autonomia frente às correntes construtivas internacionais e nos conferiria identidade própria.

Pape considerava o movimento construtivo brasileiro uma experiência bem sucedida de deglutição da cultura estrangeira, equivalente à Antropofagia (PAPE, 1980, p.22), e, ao analisar sob os mesmos critérios a linguagem plástica das tendências construtivas (erudita, industrial e universal) e a cultura material do "povo brasileiro" (o índio, o africano, o nordestino, os carnavais, os mineiros, o popular etc.) acaba por equiparar manifestações de origens e objetivos bastante distintos.

Quando analisa exemplos da cultura material popular, Pape usa uma abordagem cuja matriz é a idealização da comunidade nacional a partir das características formais da produção artística (e que termina por identificar finas qualidades artísticas na criatividade brasileira popular, atitude corrente no Modernismo ${ }^{4}$ ) e que Ihe serve para justificar a defesa da independência das tendências construtivas brasileiras frente às influências externas.

Porém, quando trata do "tropismo pelo geométrico", Pape também alude às definições feitas por Hélio Oiticica quando este escrevera em "Bases fundamentais para uma definição do Parangolé" (1964) que estas obras marcariam um ponto crucial no desenvolvimento da "estrutura-cor no espaço", principalmente no que diz respeito a uma nova definição do "objeto plástico":

Seria, pois, o "Parangolé" um buscar antes de mais nada estrutural básico na cons-tituição do mundo dos objetos, a procura das raízes da gênese objetiva da obra, a plasmação direta perceptiva da mesma. Esse interesse, pois, pela primitividade construtiva popular que só acontece nas paisagens urbanas, suburbanas, rurais, etc., obras que revelam um núcleo construtivo primário, mas de um sentido espacial definido, uma totalidade. [...] (OITICICA, 1964 in CATALOGUE..., 2004, grifos nossos)

As argumentações de Pape e de Oiticica são bastante próximas. Essa afinidade devese ao fato de terem compartilhado diversas experiências de trabalho e, sobretudo, por terem compartilhado a descoberta de uma primordial "construtividade" nas habitações populares.

Em outro texto, "Favela da Maré ou milagre das palafitas", de 1972, Pape desenvolveu alguns pontos presentes em "Tramas de caboclo" e manteve o diálogo com formulações de Oiticica sobre a natureza espacial das habitações do morro.

O texto, que se estende por breves três páginas, é resultado de reflexões originadas em aulas formuladas para o curso de arquitetura. Seu tema era a Favela da Maré, considerada especial por se fundir ao mar, como um "organismo vivo": "De cima, vendo de outra favela próxima, essa sensação de organismo vivo é gritante como um animal gigantesco adentrando o alagado" (PAPE, 1972 in BORJAS-VILLEL; VELÁSQUEZ, 2012, p.287) 
6 Pape dedicou posteriormente um artigo monográfico ao tema da cor na arquitetura popular: Morar na cor. Arquitetura Revista, n. 6, pp. 29-32. Faculdade de Arquitetura e Urbanismo - Universidade Federal do Rio de Janeiro. Rio de Janeiro, 1986.
Pape registrou as visitas de alunos da Universidade Santa Úrsula "tendo consciência de estar desbravando um terreno virgem. Levar esses jovens a um lugar que jamais pisariam de outra forma era também um desafio. Eu quero mostrar uma nova realidade estética e poética visual" (PAPE, 1972 in BORJAS-VILLEL; VELÁSQUEZ, 2012, p.287). Já de início afirmou que:

As questões menos elaboradas e menos técnicas serão sempre as mais ricas, é o broto, o início do processo criativo, que não necessariamente nos leva à perfeição das formas, ou um outro fim.

O fim não me interessa, mas o caminho percorrido, a criação em suas diferentes formas e manifestações, o invisível que nos transforma. (PAPE, 1972 in BORJAS-VILLEL; VELÁSQUEZ, 2012, p.287)

Descreve então como eram as dinâmicas das aulas, concentradas em vivências externas e diretas de interpretação do mundo. Embora falasse sobre os espaços que percorriam, deixava que os alunos fizessem suas próprias descobertas.

A fluida redação do texto revela seu apreço pela criatividade das construções num ambiente de adversidades. Entre outros pontos, destacou as cores desbotadas das paredes ${ }^{6}, \mathrm{o}$ uso inteligente da brisa nas janelas internas que interligam e refrescam as habitações - os "inventores-moradores" teriam encontrado uma solução semelhante à das casas japonesas, onde o entorno invade as construções - e destacou a permeabilidade dos espaços:

As entradas e saídas alteravam frequentemente, nada era muito permanente e eu não sentia um começo da Favela ou um final, o espaço se transformava constantemente na medida do útil ou do necessário. Como uma fita de MOEBIUS os caminhos se entrelaçavam num movimento sem fim. (PAPE, 1972 in BORJAS-VILLEL; VELÁSQUEZ, 2012, p.288)

A Favela da Maré surgia como um objeto de estudo capaz de revelar formas alternativas para repensar fundamentos arquitetônicos e espaciais pré-concebidos e, assim, desmontar preconceitos.

Emergiam ainda nessa fala de Pape alguns pontos que foram sobremaneira importantes para o movimento Neoconcreto. Um deles é a referência à fita de Moebius, privilegiada pelos neoconcretistas como forma que identifica interioridade e exterioridade, assumindo inclusive um papel metafórico, uma vez que pode dissolver fronteiras conceituais estabelecidas. Em "Catiti catiti", Pape vale-se desta forma para descrever a paisagem dos morros, que "desdobra-se entre casas, retorce-se contra os elementos naturais" (PAPE, 1980, p.61), ou comentar a casa da favela, que "tem uma exterioridade de objeto construído, mas é também a subjetividade que o levou a organizar em torno e com o seu corpo a proteção denominada casa" (PAPE, 1980, p.62-63).

Nesse ponto, também importa destacar como as formulações de Pape dialogam com a descrição de Hélio Oiticica acerca da relação entre os "Parangolés" e os espaços das habitações do morro. Para descrever esse tipo distinto de arquitetura, Oiticica se ateve a aspectos que já haviam sido elaborados nas anteriores propostas neoconcretas. 
7 Essas foram as palavras da arquiteta Lina Bo Bardi para se referir a um determinado grupo de objetos populares que colecionava. Lina coletou cerca de 2000 objetos durante o período em que residiu na Bahia, entre 1958 e 1964: enfeites de casa, fifó de lâmpada queimada, bacias e canecas de latas de lubrificante de carro, baldes de pneu velho, utensílios de madeira, boizinhos de barro, carrancas, jarros, vasos, tigelas, utensílios de cozinha, colheres, escumadeiras de arame, bule de lata de toddy, potes, pilões, santos, ex-votos, brinquedos de lata e de barro cru, cestas, vestidos e colchas de retalhos, lamparina de folha de flandres, bonecas de pano, jeep de lata de óleo etc., etc. Um amplo conjunto de objetos, muito distintos entre si, e que permite as mais diversas formas de agrupamento e de interpretação. Porém, entre a diversidade desses objetos, valorizou positivamente em seus textos aqueles "funcionais", o bule feito de lata de óleo, o balde de pneu velho, as lamparinas de folha de flandres. Distante da busca pela descoberta da "essência", do "espírito" brasileiro nas artes populares, o olhar de Lina, já tarimbado pelas análises de arquitetura, destacava a funcionalidade, o valor do "útil e necessário". Esses objetos recriados tinham a marca da invenção e ao mesmo tempo denotavam a carência material a partir da qual surgiram. Por outro lado, eles também se vinculavam à indústria, eram transformações feitas a partir de artefatos industriais. Em sua "precariedade" apontavam as dificuldades e contradições do modelo de desenvolvimento assumido pelo país. De certa maneira, Lygia Pape e Hélio Oiticica deram continuidade à redescoberta do popular idealizada por Lina Bo Bardi.
Descreveu, por exemplo, a permeabilidade e mutabilidade dos espaços nos termos de uma "organicidade estrutural":

Na arquitetura da "favela", por exemplo, está implícito um caráter "Parangolé", tal a organicidade estrutural entre os elementos que o constituem e a circulação interna e o desmembramento externo dessas construções, não há passagens bruscas do 'quarto' para a 'sala' ou 'cozinha', mas o essencial que define cada parte que se liga à outra em continuidade.

Em "tabiques" de obras em construção, por exemplo, se dá o mesmo, em outro plano. $E$ assim em todos esses recantos e construções populares, geralmente improvisados, que vemos todos os dias. [...] (OITICICA, 1964 in CATALOGUE..., 2004, grifo nosso)

Outro ponto destacado positivamente é o caráter precário, contínuo e flexível do espaço da favela, construído "sempre, a partir de um nada, um gesto, um risco no espaço", como Pape descrevera em "Catiti catiti" (PAPE, 1980, p.61) e que elaborara em "Favela da Maré" como:

A precariedade dos materiais é evidente, porém a estrutura realizada em termos arquitetônicos nesse tipo de terreno é quase surrealista e beira a perfeição criativa, aqui não se vis/umbra uma concepção urbanística, longe disso, mas uma forte concepção estética e poética de duração temporária e era justamente essa não duração que nos fazia sempre retornar. (PAPE, 1972 in BORJAS-VILLEL; VELÁSQUEZ, 2012, p.288)

Essa "precariedade-criatividade" se desdobraria nos espaços internos das habitações:

Com o tempo se começa a perceber também os materiais usados dentro das casas como sacos de batata como redes para dormir, latas de leite forrando paredes contra o frio do inverno. Pedaços de madeira velha, de todos os tamanhos e tipos eram uti-lizados, de repente, o descartável, o lixo, era reinventado como material de suporte arquitetônico real. (PAPE, 1972, in BORJAS-VILLEL; VELÁSQUEZ, 2012, p.289, grifo nosso)

A presença do "útil e necessário" é um critério que confere valor positivo aos objetos criados. A recuperação do "lixo" fazia parte da solução criativa, postura que se revelava crítica frente ao avanço do consumo. Além da necessária presença da utilidade, outro aspecto valorizado era a superação da condição de carência material, a capacidade de "riscar o limite do nada"7.

A relação que Pape e Oiticica estabeleceram com o objeto popular não visava mais a busca de um "espírito nacional", mas destacava os aspectos construtivos e a funcionalidade, como a flexibilidade extrema entre os espaços da arquitetura popular, a permeabilidade entre o dentro e o fora etc., descritas em termos mais artísticos que utilitários. A descoberta da "construtividade primitiva popular" se tornou um caminho para o prosseguimento de suas pesquisas, permitindo que construíssem um novo olhar sobre as manifestações populares e redefinissem a participação na obra de arte. 
8 Os "Ovos" eram, na verdade, cubos de 80 centímetros de largura com arestas de madeira cobertos por uma fina película de plástico azul, vermelho ou bran$\mathrm{CO}$, que as pessoas, acomodadas em seu interior, deveriam rasgar, simbolizando, performaticamente, um novo nascimento.

9 A "Roda dos prazeres" (1968) requeria a degustação de "cores" contidas em pequenos potes dispostos no chão de forma circular. Os líquidos coloridos, que deveriam ser provados por conta-gotas colocados ao lado das vasilhas, tinham sabores que nem sempre condiziam com o esperado, criando uma "ambivalência dos sentidos", nas palavras da artista.

100 "Divisor" era um imenso quadrado de tecido branco cheio de fendas regulares que deixavam à mostra as cabeças e envolviam o corpo de quem dele participava, quebrava os limites entre o artista e o público ao realizar-se pela participação coletiva.

\footnotetext{
11 São cerca de sessenta folhas, divididas entre uma parte burocrática redigida pela FUNARTE, onde constam anotações sobre prazos, abrangência da pesquisa e verbas financiadas, um breve relatório, planilhas feitas à mão atestando os lugares pesquisados (teatros, vitrines, feiras populares etc.), um encarte de imagens (o qual não consta no arquivo pesquisado no Centro de Documentação da FUNARTE, no Rio de Janeiro) e o texto em si. Sua abrangência seria Rio de Janeiro e São Paulo, zonas rural e urbana; as propagandas, industriais e artesanais, documentação impressa em cartazetes, folhinhas, iconografia publicada em jornais, especialmente os "jornais ditos populares" e elementos presentes na oralidade "popular" (PAPE, 1978, p.14).
}

Na produção de Lygia Pape e Hélio Oiticica essa aproximação à "cultura do morro" repercutiu em um tipo distinto de comportamento por parte do espectador: suas obras se converteram em propostas. Entendê-las significava participar da proposta do artista ativamente, numa completa entrega à experiência. Nessa época Pape elaborou "Ovo" 8 (1968), "Roda dos Prazeres"9 (1968) e "Divisor"10 (1968) - talvez a mais marcante de suas propostas. Como os "Bólides" (1963) e "Parangolés" (1964) de Oiticica, eram feitas a partir de materiais corriqueiros, como tecidos, potes de plástico, ripas de madeira etc., encontrados no dia-a-dia da cidade, e punham em questão a posição privilegiada do artista ao poderem ser copiadas ou recriadas. Buscando dar outro sentido à experiência cotidiana, essas obras compartilhavam a intenção de renovar o espaço e o público da arte.

\section{"A mulher na iconografia de massa" (1978)}

Se "Tramas de caboclo" e "Favela da Maré" revelam certa idealização da produção popular ainda dentro da matriz nacional-desenvolvimentista e modernista, a produção subsequente de Pape revela como esta foi sendo paulatinamente superada ou, no mínimo, redefinida.

O interesse pela "sociedade de massa", comum também à trajetória de Oiticica, norteia a produção de Pape dos anos 1970.

A pesquisa que realizou para a FUNARTE em 1978, "A mulher na iconografia de massa", definida como "um levantamento da imagem da mulher como signo gráfico [...] dentro da sociedade de massa" (PAPE, 1978, p.7), foi conceituada como um desdobramento do projeto "Eat me: a gula ou a luxúria?" e configura uma leitura da cidade contemporânea através das imagens criadas pela publicidade. Na mostra "Eat me", apresentada primeiro em São Paulo e depois no MAM-RJ, em vitrines e barracas semelhantes às de camelôs, Pape reuniu objetos comumente associados à mulher: cintas, seios e cílios postiços, batons, perucas, espelhos, pó de arroz, dentaduras, espartilhos etc. que eram apresentados ao público de forma descontextualizada para, assim, revelar seus significados ocultos (sexismo, consumismo etc.).

Segundo Pape, o projeto "Eat me" fazia parte de um conceito mais geral ao qual chamou de "Espaços Poéticos", e, dentro dele, definiu o "tema da mulher" como o "Espaço Patriarcal", que indicava as apropriações da imagem feminina e sua transformação em "objeto de consumo". Sua leitura sobre a mulher na iconografia de massa une aspectos relativos a um espaço urbano emergente e a questão do feminino junto a um repertório de imagens e ideias próprias ao universo da arte - mistura que torna estimulante a sua leitura ${ }^{11}$. Seu trabalho busca entender a poética de um espaço urbano contaminado pelas imagens de massa e nelas apontar potencialidades criativas.

Pape inicia seu texto sendo categórica: na cultura de massa a leitura de códigos visuais associados à figura feminina tornara-se pobre e padronizada. A imagem da mulher serviria como apelo ao consumo cuja carga pretensamente erótica remeteria a uma "apropriação deturpada da figura feminina" (PAPE, 1978, p.7). Essa é a tônica que domina sua análise. 
A primeira parte de seu relatório traz as definições dos conceitos que utiliza para analisar as imagens femininas ("Função Poética", "Morar na cor", "Museu imaginário" e "Mensagem Poética") e a segunda a análise das fotos que coletou, divididas entre aquelas que analisa formalmente e interpreta segundo a relação que estabelecem com o meio urbano no qual se inserem (Seção "Análise das fotos") e aquelas que ilustram sua leitura sobre o uso da imagem feminina na publicidade (Seções "O corpo devorado" e "Espaço patriarcal").

Em "Função Poética" encontramos um trecho que claramente revela sua postura de "VER" como artista - por isso o destacamos em nosso texto. Relatando uma noite enevoada em que deixava o Museu de Arte Moderna, descreve os efeitos de difusão da luz causados pela neblina em alguns anúncios daquele entorno como uma verdadeira experiência estética:

Uma noite, há muitos anos, eu Ivan Serpa e Darcilio Lima saíamos do Museu de Arte Moderna do Rio de Janeiro quando deparamos com um espetáculo indescritivel: toda a área em torno do museu o jardim de pedras, o chafariz, os gramados que se alternam em ondas verdes e que alongam por um lado até os letreiros da Varig e de outro se distanciam pelo Aterro afora, era uma coisa só, tomada por nevoeiro denso e branco que escondia tudo e amortecia até mesmo os ruídos. Pois nesse vapor, nós víamos pairando como nuvens leves, vibrantes, difusas, enormes manchas de cor vermelha, verde, azul. Não havia linha de horizonte, tudo se confundia como um espaço esférico e oco onde nós nos inseríamos também, envolvidos por aquela luminosidade colorida. Boiávamos juntos como bolhas soltas. Esse espetáculo pode ser comum naquela área, mas para mim, foi uma revelação. Eu tive como que uma revelação de $V E R$. Dali para sempre eu não veria as coisas de maneira única, presa aos significados aparentes, mas também ligada a outros, emergentes segundo a minha vontade, todos sempre presentes e abertos, como sinais novos e novos significados - a partir de um mesmo significante. (PAPE, 1978, p.6'-7')

Nos parágrafos seguintes, Lygia enfatiza como essa transformadora experiência ampliou sua forma de leitura da cidade e, em "Museu imaginário", formula um novo método interpretativo de imagens. De início, constata que o convívio com os veículos de comunicação de massa já faz parte do cotidiano e se espalha por todas as atividades, como um "poluidor visual" aceito passivamente, mas que também estabelece uma "nova poética" no espaço que ocupa, que, apesar de determinar condutas voltadas ao consumo, seria capaz de criar "espaços artísticos". Antes de abordar uma propaganda

12 Para melhor articular sua proposta, Pape mescla referências a Jacobson e Humberto Eco. Do primeiro cita um excerto sobre a ambiguidade de estrutura da mensagem poética a qual possibilita interpretações múltiplas e obriga a fixar a atenção sobre a própria estrutura. Lembra, citando Eco, que o receptor substituiria um código externo global por um relacionado à sua própria sensibilidade e inteligência. Seu entendimento particular sobre a teoria da abertura da obra de arte the amplia as possibilidades de análise. considerando sua finalidade, propõe abordá-la como processo "mais ou menos livre dos significados que vão lhe determinar a forma".

Transgredir os métodos utilizados pela própria sociedade de massa, seria, para Pape, "uma atitude anarquista e interessante", pois determinaria novos enfoques e novos suportes para a ação do "homem-inventor-criador". Essa nova perspectiva teria ainda um "dado de humor grandioso" ao anular a monotonia que "adormece o olho, neutraliza a percepção e empobrece a existência diária" (PAPE, 1978, p.13'). Seria preciso desconsiderar o texto para apoiar-se no projeto plástico ou na imagem em si: "Faz-se então uma corrente de relações novas entre as várias figuras que se justapõem imageticamente pela cidade". O receptor, então, pôr-se-ia atento à estrutura dos "significantes" ${ }^{12}$. Sua leitura, que passa menos pela comunicação da 
mensagem em si, dialoga com as definições "poéticas" formuladas nas páginas anteriores.

Essa metodologia fica mais clara quando passa à "Análise das fotos", onde analisa conjuntos de imagens formadas por cartazes colados lado a lado em partes da cidade. A possibilidade de criar narrativas através das imagens pareadas ao acaso é apontada, por exemplo, em figuras onde um personagem "dialoga" com outros, de cartazes distintos: "[...] como o cômico de televisão olhar matreiro que parece saber o que se passa no 'andar' de baixo ou seja o outro cartaz do filme 'Amada Amante'" (PAPE, 1978, p.19').

As imagens ainda poderiam formar composições como as descritas nas figuras que mostram a vitrine de uma loja de vestidos de noivas na Rua São Caetano, em São Paulo: "Uma figura de mulher toda paramentada e a faixa de 'liquidação' sobre ela" (PAPE, 1978, p.22'). Pape afirma que, abstraído o contexto, ter-se-ia uma visão dadaísta: "Elas tornam-se então objetos do absurdo ou objetos-trouvé" (PAPE, 1978, p.22').

$\mathrm{Na}$ interpretação de parte das imagens, Pape se atém às mudanças de significados decorrentes do contexto no qual os cartazes se inserem. A paisagem comporia um "fundo" distinto para a "figura" e alteraria e ampliaria seus significados. É o caso de um cartaz com motivos infantis fixado na parede de um estacionamento: "mas a imagem da 'Branca de Neve' em meio aos carros de um estacionamento liquida de vez o mito infantil das histórias de fada. Como conciliar a 'Branca e seus anões' dentro de tal contexto? É nessas situações que a imaginação do passante pode desenvolver seus devaneios poéticos" (PAPE, 1978, p.20').

Descreve ainda uma propaganda que mescla as imagens dos cartazes ao ambiente urbano, a propaganda de maiôs Lycra, segundo ela "a melhor imagem coletada":

Melhor e mais convincente é o anúncio de maiô da Lycra. Uma figura maravilhosa, loura, insinuante, sensual se lança num mergulho pelo espaço da cidade. Surgem então as situações as mais ambíguas e curiosas: a loura flamante em mergulho sobre os passantes de uma grande avenida. Caindo sobre os carros, mergulhando decidida nos gramados urbanos. (PAPE, 1978, p.19')

A maneira como analisa as imagens vindas da publicidade se distancia da objetividade característica dos trabalhos científicos: sua visão segue critérios estéticos e mostra como, desvinculada da sua função instrumental de vender, essas imagens permitem uma forma aberta de leitura, que prenuncia, inclusive, novas propostas de trabalhos artísticos.

Segue à "Análise das fotos" o texto intitulado "O Corpo devorado", no qual Lygia analisa, finalmente, a questão do feminino. Inicia informando que estatisticamente as imagens femininas correspondem a $70 \%$ dos anúncios pesquisados e que se apresentam de várias maneiras, desde o corpo inteiro até "pedaços" que seriam "as partes configuradas de maior índice erótico, de maior carga de apelo à libido do homem" (PAPE, 1978, p.23').

Entre os "pedaços" da figura feminina, Pape destaca a boca. "Ela é ao mesmo tempo boca, vagina, olho e boca novamente só que famélica, devoradora, antropofágica" 
13 Na proposta feminista encontravam-se tentativas de localizar a mulher política, estética, histórica e psicanaliticamente. No contexto internacional do período, sobretudo no norte-americano, artistas como Yoko Ono, Eva Hesse, Adrian Piper, Susan Hiller, Miriam Schapiro, Louise Bourgeois, Mary Kelly, Mira Schor, Cindy Sherman, Judy Chicago e Bárbara Kruger, entre outras, responderam de formas diferentes às questões sobre o feminino.

\footnotetext{
14 Nesse sentido, o exemplo de Mário de Andrade é paradigmático. Ele protagonizou o "descobrimento" do Brasil, percorrendo nas décadas de 1920 e 1930 o interior do país para registrar manifestações folclóricas num período em que artistas e intelectuais ainda contribuíam diretamente para os quadros do Estado, amparados em um amplo projeto político-cultural que incorporava o elemento popular como dado essencial. A pesquisa e reelaboração da produção musical popular realizada pelo maestro Heitor Villa-Lobos também é uma referência para se analisar o período. As fontes musicais populares coletadas em pesquisas eram retrabalhadas segundo parâmetros eruditos e postas de volta à circulação.
}

(PAPE, 1978, p.23'-24'). Haveria também convenções na apresentação de cada parte do "corpo a ser devorado": por exemplo, "As bocas são todas sangrentas, rubras, tenras, entreabertas à espera de algo que o imaginário de cada um enriquece a partir de seus repertórios libidinosos" (PAPE, 1978, p.24').

Sua abordagem não se pretende militantemente feminista, mas evidencia o impacto do tema naquele momento, em que se realizavam diversas propostas artísticas sobre as questões de gênero ${ }^{13}$. Logo de início, Pape localiza seu trabalho como "documento diferenciado no campo das artes plásticas": utiliza-se de uma pesquisa institucional para ampliar seu campo de ação. Apesar de haver limitações, a pesquisa tanto testemunha seu conhecimento desta vertente como também a situa como questão a ser enfrentada.

Por outro lado, o texto de Pape indica como a artista já possuía uma consciência sobre o desenvolvimento e os discursos da arte pós-minimalista norte-americana.

Outro ponto a destacar é a investigação "poética" das imagens de massa. Se retomarmos a descrição de sua lembrança do nevoeiro a modificar a percepção das luzes dos anúncios, "como enormes manchas de cor", veremos como a ela subjaz a ideia de que ao artista, repercutindo formulações modernas, caberia um papel crucial: superar a indústria cultural pela criação. Na tentativa de recuperar o poder criador, superando a negatividade das constatações (preconceitos, moralismo, consumo), recoloca a questão da imagem da mulher como tema a ser elaborado, recriado, redefinido pela arte. Tal postura provém de seu repertório teórico, mas, sobretudo, de sua percepção e sensibilidade nutridas pelas artes plásticas. Seus interesses, embora extrapolassem esse meio, nunca abandonavam o eixo estético.

A "função poética" indica que Pape (como também Oiticica) via possibilidades em trabalhar a partir da cidade, mesmo aquela permeada pelas degradadas imagens da indústria cultural. Em "Tramas de caboclo..." e "Favela da Maré...", Pape encontrara na produção popular a renovada fonte para repensar a arte de vanguarda de um país periférico. Esse interesse, agora deslocado para a cultura de massa, revela, por um lado, certo desencantamento e, por outro, a permanência do seu interesse pelo "popular", já perante uma nova configuração.

\section{Considerações}

Se apresentamos no decorrer dessas páginas abordagens da artista Lygia Pape a duas diferentes dimensões do universo da cultura "não erudita" e essas leituras se apresentaram altamente positivas (genuína referência para a arte de vanguarda brasileira ou material necessário para uma renovada reflexão sobre a cidade), também nos cabe pensar sobre as motivações que conduziram a artista a essas posições.

Longe de ser uma prática nova, o encontro com o popular esteve presente de maneira efetiva na produção cultural moderna brasileira, que, em parte, se apoiara no encontro com este "outro" como fonte de revisão e proposição de novos parâmetros, não apenas estéticos ${ }^{14}$. Ao tentar entender o que a procura pelas "raízes brasileiras" significava, não só para Lygia Pape, mas também para Hélio Oiticica, foi necessário encarar as dificuldades advindas da inexistência de uma visão consensual sobre o próprio conceito de "popular" ou "cultura popular". Seu emprego revela uma ambivalência, seja por 
15 Além de problematizar tal denominação, é necessário atentar para como a crítica de arte recuperou essas discussões. Lembrando Pedrosa (apud ARANTES, 1983, p.32-34), a distinção entre os termos "arte culta" e "arte popular" teria surgido na época moderna, na sociedade capitalista, com a formação da burguesia e a divisão da sociedade em classes, constituindo um dos "aparelhos ideológicos" burgueses uma vez que a "arte popular" fora sempre um produto excluído das honras da historiografia da arte. Para Chauí (1984), a denominação "cultura do povo" viria dos próprios intelectuais. Tal expressão teria surgido da constatação da diferença, da oposição e do reconhecimento da luta de classes. O termo "cultura popular", sob um prisma marxista, representaria uma ideia de dominação, as ideias dos dominados em relação a uma cultura dominante, que estaria na esfera da "arte culta". parte das instituições que então surgiam para gerir a Cultura, seja por parte de artistas e intelectuais que se acercavam do tema, então em intensa discussão ${ }^{15}$. Não é difícil perceber que, no período, o "popular" se constituía como campo de disputa.

De início podemos pensar que a estilização da figura do morador da favela vinha preencher lacunas no que se configurava como o estilo de vida da emergente classe média no Brasil do Milagre Econômico de meados de 1970, fruto da urbanização acelerada, da consolidação da sociedade urbana e da indústria cultural. Mais afluente que nunca (experimentava-se um inédito crescimento econômico de 10\% ao ano), mas constrangida por todos os lados, ela acabava por expressar essa insatisfação em diversas formas de manifestação cultural. A ênfase nos aspectos positivos atende a essa classe de insatisfações.

A "arquitetura popular" se configurava quase como um lugar à parte: os moradores do morro acabariam se atendo, forçados pela carência, apenas às necessidades básicas, estando desta maneira "livres" das necessidades artificiais impostas pelas pressões do consumo. Assim, seriam impelidos a exercer sua criatividade e a ter um contato com o próprio corpo, com o ambiente e com as outras pessoas mais "autêntico". Esta visão recriava e atualizava uma série de lugares comuns em relação às manifestações populares.

Durante a ditadura militar, a "favela" tornara-se um ponto recorrente na cultura e no discurso político da oposição. A visão de Lygia e de Hélio sobre seus espaços se mostra distinta na medida em que se afasta da visão corrente da oposição de esquerda do período, que tendia a retratá-la por meio de uma arte "engajada" que a tomava como paradigma das injustiças e desequilíbrio no desenvolvimento social brasileiro. Em contraste, sua abordagem era decididamente positiva quanto às potencialidades da "cultura popular".

Hélio e Lygia compartilhavam ainda outro ponto: utilizavam na análise da cultura popular da favela procedimentos análogos aos empregados em suas propostas artísticas. Daí emergir uma espécie de leitura neoconcreta da favela que se apoiava em aspectos como a continuidade e permeabilidade entre espaços de dentro e de fora das habitações, expressa, por exemplo, na referência à fita de Moebius. Esse ponto é central na argumentação de "Tramas de caboclo" e "Favela da Maré" e na dissertação "Catiti catiti, na terra dos brasis". A arte da neovanguarda brasileira encontraria sua identidade e relevância internacional na medida em que entrasse em diálogo com o "popular".

Este diálogo configura-se ainda mais complexo quando observamos o interesse de Pape pela imagem da mulher na "iconografia de massa": ainda que a artista continue a lidar com o material provindo do cotidiano urbano, neste momento trabalha a partir de outros tipos de referências e questões, como se uma nova camada se sobrepusesse às questões anteriores.

Assim como Lina Bo Bardi, Lygia Pape e Hélio Oiticica descobrem a existência de uma "primitividade construtiva" no popular. A ressignificação de resíduos da indústria (potes, vidros, caixas, plásticos etc.) recolocava sob nova forma a crítica ao desenvolvimento dependente que Lina iniciara. A proposta de incorporação da produção popular num 
amplo projeto que visasse o desenvolvimento alternativo e independente para o Brasil é redefinida pelos artistas, que, distantes de um "projeto" para a nação, contrapõem não apenas a dimensão do imediato, do urgente, mas também a da criatividade inerente à precariedade cotidiana popular. Se o objeto projetado pelo desenho industrial virara consumo, haveria que se repensar outras estratégias.

Enquanto as experimentações artísticas derivadas do encontro desses artistas com a arquitetura, cultura e o samba do morro haviam dado origem a propostas que requeriam a participação ativa do público, como nos "Parangolés", "Bólides", "Divisor" e "Roda dos Prazeres", na fase seguinte, os artistas aumentaram o escopo de suas referências. Tanto Pape quanto Oiticica perceberam que falar de "popular" nos anos 1970 correspondia a construir novas referências que deveriam se distanciar das "raízes brasileiras" modernistas incorporando nas análises as imagens difundidas pela publicidade, pela televisão e pelo rádio, por cartões postais, revistas ou objetos plásticos tornados "populares" pela indústria de gadgets, pelos grandes anúncios dos outdoors, produtos de segunda linha, indústria cultural, música, cinema e literatura, e, enfim, em todos os discursos que muito rapidamente haviam passado a permear a experiência da cidade (e não apenas a da classe média ou alta).

Pape e Oiticica não são os únicos a perceberem essa substancial mudança. Estas questões estão também presentes na produção de outros artistas. Um caso típico é a obra "A Bela Lindonéia" ou "A Gioconda do Subúrbio", elaborada por Rubens Gerchman em 1966. A obra reproduz a imagem de uma jovem de 18 anos envolvida em assassinatos que impressionaram as camadas populares e que foram amplamente difundidos nos jornais sensacionalistas da época. A imagem da jovem é o ponto de partida para o trabalho do artista, que dá a Lindonéia um tratamento semelhante ao que a pop art dera às imagens de uma Marylin Monroe, porém sua aproximação se distancia do glamour, submetendo-a a um tratamento que remete às limitações econômicas e técnicas da imprensa popular da época. Não por acaso esse quadro deu origem a uma canção de Caetano Veloso e Gilberto Gil. Ou seja, chamou a atenção de duas das principais figuras do Tropicalismo, que tentava um novo entendimento da cultura brasileira, ultrapassando a forma da dualidade entre arcaico e moderno.

Essa inflexão está presente tanto na trajetória de Pape quanto na de Oiticica, nas vivências em Londres e Nova lorque ou na nova experiência com a cidade do Rio de Janeiro. Mas a ocorrência de tal inflexão extrapola suas carreiras. Pode-se dizer que a estrutura do país estivesse enfrentando importantes mudanças e que, mesmo internacionalmente, depois de 1968, as expectativas depositadas no "povo", na classe operária, estivessem diminuindo, recolocando em outros termos a questão do sujeito

16 Nesse período, os liberais norte -americanos optaram por seguir uma postura de apoio a reivindicações de grupos identitários. Todo esse arco de reivindicações acabou sendo definido como as "políticas de identidades". Da mesma forma como o feminismo pode ser entendido como parte desta estratégia política, também se pode pensar a produção de outros artistas como seguindo essas posturas. histórico, agente de mudanças. O trabalho em arte enfocando as "minorias" ganhava então cada vez maior protagonismo ${ }^{16}$. Neste segundo momento, que transcorre durante a década de 1970, os artistas continuam sua pesquisa interessados em ver como a produção da indústria cultural permeia a vivência urbana emergente. Nesse movimento, desperta seu interesse a cultura produzida por grupos específicos, com identidades próprias, e as questões ligadas ao feminino, etnias, gênero, contracultura etc. começam a emergir em seu trabalho, e não apenas nele.

Se encontramos nos dois primeiros textos de Pape uma matriz ainda próxima à do modernismo brasileiro, o último leva a pensar sobre as discussões que então aconteciam 
no contexto norte-americano e nas novas propostas para a arte de ponta, que têm como interlocutor (direto ou indireto) o debate feminista.

Na produção de Hélio Oiticica da década de 1970 também encontramos uma autocrítica à sua produção anterior ligada à Mangueira. Oiticica já morava há cerca de três anos em Nova lorque quando produziu suas "Cosmococas", que demonstram o quanto, em vez de seguir elaborando as referências da cultura popular brasileira, o artista já travava diálogo com a produção nova-iorquina.

Se nos "Parangolés" da Mangueira sua preocupação fora promover através da arte o contato renovado (sem as mediações das convenções artísticas ou as do consumo) com o mundo, instaurando um novo sentido para as práticas cotidianas, nas "Cosmococas" ele desenha uma nova estratégia para (re) "formular pela primeira vez" o mundo (Gullar, 1959). Propõe ambientes nos quais o participador é solicitado a participar justamente a partir dos elementos descartados do consumo.

HO chamou de Bloco de experiências "Cosmococa - Programa in progress" (1973-74) um conjunto de nove proposições de instalações acomodadas em caixas que tinham instruções para a criação de situações "faça você mesmo". Via de regra, são trabalhos a quatro mãos (com Carlos Vergara, Silviano Santiago, Thomas Valentim etc.) e sua origem encontra-se na parceria com Neville d'Almeida, na vontade de "desconstruir" o cinema e no seu interesse pelo Cinema Marginal.

Nas "Cosmococas", o participador, vencendo a passividade do cinema tradicional, deveria articular as imagens por si mesmo, construindo sua própria narrativa. Nos slides que projetava em algumas paredes dos ambientes propostos, $\mathrm{HO}$ mesclava a imagens bastante difundidas de célebres figuras como Marylin Monroe, Jimmy Hendrix, Yoko Ono, Mick Jaeger (presentes em capas de discos ou livros em destaque na época) camadas de desenhos feitos com cocaína. Às imagens de massa, as "Cosmococas" mesclavam elementos vindos do universo "underground" de Nova lorque.

As imagens deveriam ser vistas em ambientes próprios que variavam de acordo com o bloco experiência e incluíam redes para deitar, piso feito de espuma, elementos como balões de ar, colchões, sólidos geométricos feitos também de espuma, lixas de unha etc. que potencializariam a capacidade do espectador remontar a narrativa das imagens projetadas.

$\mathrm{Na}$ "Cosmococa", HO operava reduzindo a forma degradada "cine-entretenimento" a seus elementos constitutivos: filme, espaço e tempos fixos da projeção, comportamento do espectador na recepção (corpo que olha, sentado sem reação), arquitetura de palco e plateia para, então, rearticulá-los pela colisão entre a ausência de narrativa e a proposta ambiental. Seu resultado eram Kits portáteis, que poderiam ser reproduzidos em massa e vendidos, contendo os slides e todo material necessário para a realização de "Cosmococas" em casas, apartamentos, festas etc.

Nesse sentido, $\mathrm{HO}$ trabalha desde dentro da lógica de produção da cultura de massa, como o próprio rock and roll. As "Cosmococas" demonstram ainda como as artes plásticas se abriam para esse mundo e tentavam interferir nele. 
No texto de Asbury (2008) encontramos uma análise de como a descoberta do rock and roll em Nova lorque foi fundamental para que Oiticica revisasse seus parâmetros a respeito do samba. Para o autor, as conotações primitivistas se esgotariam ao se considerar a extensão da trajetória de $\mathrm{HO}$ e como (re)pensou a experiência da dança quando entrou em contato com o rock. Oiticica enxergava no êxtase dionisíaco do samba um caminho na investigação da experiência estética, outro meio de proporcionar "ao indivíduo de hoje, a possibilidade de 'experimentar a criação'" (OITICICA, 1966 in CATALOGUE... 2004). Nesse sentido, a cultura do samba aparecia como um imenso campo a ser explorado. Porém, nos textos em que escreve sobre esse período passado em Nova lorque na década de 1970, o rock é alçado a instrumento de descoberta do corpo, papel antes designado ao samba:

[...] descobri q o q faço é música e q música não é "uma das artes" mas a síntese da conseqüência da descoberta do corpo: por isso o ROCK p. ex. se tornou o mais importante para eu pôr em xeque dos problemas chave da criação (o SAMBA em q me iniciei veio junto com essa descoberta do corpo no início dos anos 1960: PARANGOLÉ e DANÇA nasceram juntos e é impossivel separar um do outro): o ROCK é a síntese planetário-fenomenal dessa descoberta do corpo. (OITICICA, 1980 apud JACQUES, 2001, p.41, grifo nosso)

Apresentando, inclusive, algumas vantagens:

O samba é uma coisa mais ligada à terra, ligada a coisas míticas das quais o rock prescinde. O rock já sintetiza tudo isso, você já é iniciado desde que ele te atinge. O samba, eu tive que ir a ele. (OITICICA, 1978 apud JACQUES, 2001, p.41, grifo nosso)

Se retomarmos as análises do próprio HO sobre sua trajetória, veremos como a fase de seu envolvimento com a Mangueira é considerada uma preparação para o seu desenvolvimento artístico posterior. Como lembra Favaretto (2007), suas últimas entrevistas, datadas do período em que chega de volta ao Brasil, em 1978, depois de oito anos vivendo em Nova lorque, revelam como os seus trabalhos recentes configuravam "uma anamnese daquele percurso que então considerava um prelúdio ao que seria a sua verdadeira criação". Disse Oiticica: "De repente eu cheguei à conclusão que tudo

17 Na produção de Pape das décadas seguintes, encontramos desdobramentos dos interesses presentes nestes três textos. A partir desse período, inicia uma pesquisa mais formal voltada às possibilidades de "ressensualizar" materiais e à investigações sobre materialidades como chapas de aço ("Amazoninos") e néon ("O olho do guará"). Em "Sedução" (1995), por exemplo, Pape construiu corações formados por embalagens de bombons, reimprimindo "virtudes" aos materiais descartados, representantes do consumo. Por outro lado, ela constituiu uma importante série de trabalhos que tem como questão central a relação entre os tupinambás e a cidade do Rio de Janeiro. o que eu fiz antes era um prólogo para o que está aparecendo agora" (OITICICA, 1978 in OITICICA FILHO; VIEIRA, 2009, p.180).

Para Pape e Oiticica, dar continuidade a suas pesquisas em meados dos anos 1970, significava ter um olhar aguçado para a produção da indústria cultural, seguir os meandros de sua apropriação ${ }^{17}$. O projeto "Eat me: a gula ou a luxúria?" (1975-1978) dá a medida dessa transformação: a associação entre consumismo e sexismo combinava a pesquisa da "arquitetura" ao mundo vindo do comércio informal popular.

Na mostra "Eat me", apresentada primeiro em São Paulo na Galeria Arte Global e depois no MAM-RJ, em vitrines e barracas semelhantes às de camelôs estavam reunidos objetos corriqueiros diretamente referentes à mulher: cintas, seios e cílios postiços, batons, perucas, espelhos, pó de arroz, dentaduras etc.

Na primeira exposição, Lygia dividiu o ambiente em duas partes, uma com luzes vermelhas e a outra com luzes azuis. No meio de cada sala montou uma estrutura cúbica 
18 Os artigos "A Querela do Brasil" (Carlos Zilio), "Ideologia da cultura brasileira" (Carlos GuiIherme Mota) e "Planejamento ambiental, 'Desenho' no impasse" (Lina Bo Bardi) centram o foco em diversas dimensões implícitas no feixe de questões despontadas pelo "nacionalismo" e/ou pelo "modernismo brasileiro" nos números de Malasartes. Problematizam a questão da relação entre arte e "identidade nacional" e o desenvolvimento de uma arte local contemporânea independente, produzida no Brasil, e não "brasileira". Carlos Zilio em "A Querela do Brasil" coloca a questão da dependência de modelos externos nas artes plásticas defendendo o interesse por uma concepção particular de expressão vinculada à "nossa realidade" (MALASARTES n.2, 1976, p.8). Ver MACHADO; SANTOS, 2012. de ferro, de onde pendiam várias lâmpadas, e as cobriu com um tecido transparente, como numa barraca. Nelas havia saquinhos de papel com a inscrição impressa em preto "objetos de sedução", onde estavam contidos calendários de mulheres nuas, pelos, loções afrodisíacas, amendoim, espelhos junto a textos feministas que podiam ser comprados ao preço de $\mathrm{Cr} \$ 1,00$ (um cruzeiro), o que, segundo Lygia, "também era uma forma de contestar o mercado de arte. [...] As pessoas mais diversas compravam esses objetos de arte". Comprar e levar para a casa tais objetos, adquiridos numa exposição na qual se problematizava a mulher como objeto de consumo, implicava em ressemantizá-los - em uma das entrevistas nas quais descreveu que carimbava de batom e assinava cada saquinho vendido, Lygia brincou que os beijava e depois os "assassinava" (PUPPO, 2004), fazendo referência à mudança de sentido que promovia -, os "objetos de sedução", na categoria de objetos de arte, evidenciariam seus significados ocultos (MACHADO, 2008, p.81). Não demorou para que a exposição de Pape fosse fechada pela censura.

No MAM do Rio de Janeiro, na Área Experimental, onde remontou a exposição, Lygia fez um espaço todo negro com três tendas que sustentavam a frase "Eat me: a gula ou a luxúria?" escrita em néon. Nestas tendas também vendia os "objetos de sedução". Algumas bancadas exibiam artefatos desse universo corrompido; uma delas mostrava objetos como perucas, seios, dentes e cílios postiços, outra cabelos e maçãs, uma ainda exibia fotos e a outra textos feministas.

Nesta simulação de feira de camelôs vemos as duas referências que embasam os textos de Pape interagindo. Interessa ver como a artista articula essas dimensões, implicando ao universo popular as decorrências da indústria cultural.

Não à toa, "Eat me" apareceu no segundo número da revista Malasartes. Esta revista de curta duração (apenas três números) foi publicada por artistas e críticos então emergentes como Ronaldo Brito, Carlos Zilio e José Resende e tinha como ponto central a análise e a discussão do circuito de arte. Seus artigos abordavam a questão da circulação das obras e da possibilidade de interferir no sistema de arte, então em consolidação. Alguns eram dedicados à republicação de textos importantes para o desenvolvimento da arte recente no Brasil e parte deles atualizava o debate da arte contemporânea traduzindo textos internacionais. Junto a isso, a revista também construía uma crítica ao projeto nacional popular, que pode ser lida a partir de um conjunto de artigos como "A Querela do Brasil", de Zilio ${ }^{18}$, e de produções individuais de artistas brasileiros como a reportagem fotográfica de Carlos Vergara sobre o bloco carnavalesco "Cacique de Ramos", a apresentação da exposição "Eat me: a gula ou a luxúria?", de Lygia Pape, e o grupo de fotografias "Satélites" de Miguel do Rio Branco, sobre as habitações das cidades que cercam Brasília. São artigos e trabalhos práticos que guardam a forte referência ao universo popular emergente, fruto do "milagre econômico" brasileiro, mas que, no entanto, se distanciam das práticas artísticas do modernismo brasileiro.

Malasartes retrata uma nova dinâmica das artes plásticas em um momento rumo à abertura democrática. Na época, as artes ensaiavam novas aproximações a reconfigurada cultura não erudita brasileira.

Como todo momento de transição, o emergente convive com o pré-existente. Esta tensão percorre a obra de Lygia Pape e, na verdade, a impulsiona. Os textos foram 
selecionados por representarem pontos estratégicos desta tensão dentro da qual ela trabalhou. Indiretamente, a produção de Pape e Oiticica reflete essas mudanças, que, atentando para outros aspectos do urbano, recriam mais uma vez a forma de relação entre arte e realidade.

\section{Bibliografia}

ARANTES, Otília. Mario Pedrosa diante da arte pós-moderna. Arte em Revista n.7, CEAC. São Paulo, 1983.

ASBURY, Michael. O Hélio não tinha ginga. In: BRAGA, Paula. (org). Fios soltos: a arte de Hélio Oiticica. São Paulo: Perspectiva, 2008.

BORJAS-VILLEL, Manuel J.; VELÁSQUEZ, Teresa. (curadoria). Lygia Pape: espaço imantado. Textos de Paulo Herkenhoff [et al.]. São Paulo: Pinacoteca do Estado, 2012.

CATALOGUE RAISONNÉ HÉLIO OITICICA. Textos originais de Hélio Oiticica e outros em mídia digital - versão preliminar do Catalogue Raisonné Hélio Oiticica. Rio de Janeiro: Projeto Hélio Oiticica, 2004. 3 CD-ROM.

CHAUÍ, Marilena. Seminários. O nacional e o popular na cultura brasileira. São Paulo: Ed. Brasiliense, 1984.

FAVARETTO, Celso. Tropicália: a explosão do óbvio. In: BASUALDO, Carlos (org). Tropicália: uma revolução na cultura brasileira (1967-1972). São Paulo: Cosac \& Naify, 2007. Vários autores.

GULLAR, Ferreira. Diálogo sobre o não-objeto. 1959. Disponível em: <http://www.literal.com. br/ferreira-gullar/por-ele-mesmo/ensaios/dialogo-sobre-o-nao-objeto/>. Acesso em: 10 maio 2013.

JACQUES, Paola Berenstein. Estética da ginga: a arquitetura das favelas através da obra de Hélio Oiticica. Rio de Janeiro: Casa da Palavra, 2001.

MACHADO, Vanessa Rosa. Lygia Pape: espaços de ruptura. Dissertação (Mestrado). Universidade de São Paulo, Escola de Engenharia de São Carlos. São Carlos, 2008.

MACHADO, Vanessa Rosa; SANTOS, Fábio Lopes de Souza. A Revista Malasartes, a crítica ao projeto político-cultural do modernismo e a produção experimental dos anos 1970. In: Anais do VIII Encontro de História da Arte: História da Arte e Curadoria, 2012, Campinas.

MALASARTES. Rio de Janeiro, Números 1, 2 e 3. Rio de Janeiro. Imprinta. Setembro de 1975/ junho de 1976.

MATTAR, Denise. Lygia Pape - Intrinsecamente Anarquista. Rio de Janeiro: Relume Dumará: Prefeitura Municipal do Rio de Janeiro, 2003.

OITICICA FILHO, César; VIEIRA, Ingrid (org.). Hélio Oiticica. Rio de Janeiro: Beco do Azougue, 2009.

ORTEGA, Sheila Christina. Lygia Pape, indigenismo e engajamento. Dissertação (Mestrado) Universidade Julio de Mesquita Filho, São Paulo, 2004.

PAPE, Lygia. A mulher na iconografia de massa. (Relatório de Pesquisa). FUNARTE, Rio de Janeiro, 1978.

Catiti catiti na terra dos brasis. Dissertação (Mestrado). Universidade Federal do Rio de Janeiro. Rio de Janeiro, 1980.

Favela da Maré ou milagre das palafitas (1972). In: BORJAS-VILLEL, Manuel J.; VELÁSQUEZ, Teresa. (curadoria). Lygia Pape: espaço imantado. Textos de Paulo Herkenhoff [et al.]. São Paulo: Pinacoteca do Estado, 2012. 
PAPE, Lygia. Lygia Pape - Entrevista a Lúcia Carneiro e lleana Pradilla. Rio de Janeiro: Nova Aguilar, 1998. Coleção Palavra do artista.

Tramas de caboclo ou a geometria do mato (s/d). In: BORJAS-VILLEL, Manuel J.; VELÁSQUEZ, Teresa. (curadoria). Lygia Pape: espaço imantado. Textos de Paulo Herkenhoff [et al.]. São Paulo: Pinacoteca do Estado, 2012.

PUPPO, Eugênio (Ed. e org.). Cinema marginal brasileiro e suas fronteiras: filmes produzidos nos anos 60 e 70. Rio de Janeiro: Heco Produções. 2004. 